\title{
Las movilidades del turismo y las migraciones de amenidad: problemáticas y contradicciones en el desarrollo de centros turísticos de montaña ${ }^{1}$
}

\author{
Rodrigo González², Adriana Otero², Lía Nakayama² y Susana Marioni²
}

\begin{abstract}
RESUMEN
Las distintas movilidades que el turismo genera, construyen y deconstruyen los destinos turísticos que, como lugares de juego, compiten en el mercado de viajes para ser sustentables en el largo plazo. Cumpliendo este rol, los gestores de las políticas turísticas de los destinos en la mayoría de los casos se focalizan en generar condiciones para atraer inversiones a cualquier costo. Se genera así un nuevo tipo de movilidad, ya no de turistas, sino de personas que desean una mejor calidad de vida y encuentran distintos tipos de desarrolladores de sus anhelos. Este segundo tipo de movilidades produce lo que se denomina la sombra del turismo. El fenómeno de migración de amenidad puede ser interpretado entonces como una sombra, ya que las movilidades que produce son regresivas en términos de desarrollo local. Este artículo analiza cuatro casos de estudio en Argentina: San Martín de los Andes, Villa La Angostura, El Bolsón y Villa General Belgrano, con el objeto de contribuir a una mejor comprensión de los cambios que produce la migración de amenidad en centros turísticos de montaña. Se puede extraer que la principal amenaza que significa este proceso en términos de desarrollo local es su poder para ocultar la falta de competitividad del sector turístico en estos destinos.
\end{abstract}

Palabras clave: Migración de amenidad, destinos turísticos de montaña, competitividad, desarrollo local.

\begin{abstract}
Tourism mobilities highlight that many different mobilities shape the places where tourism is performed and drive the making and unmaking of tourism destinations. As sites of play, tourism destinations compete in travel market to be sustainable in the long term. Playing this role, managers of tourism destinations in most cases misunderstand it as a simple generator of attracting conditions for a new kind of mobility

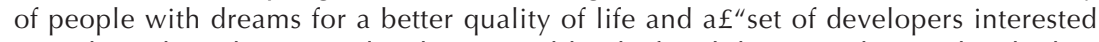
in making their dreams real". This second kind of mobilities produces "the shadow of tourism". Thus, amenity migration is viewed as a shadow because the kind of mobilities it caused could be interpreted as regressive in terms of local development. This paper analyze four cases of study: San Martín de los Andes, Villa La Angostura, El Bolsón and Villa General Belgrano in Argentina to better understand the kind of changes amenity migration produce. The principal threat that amenity migration means in terms of local development is its power to hide the lack of competitiveness of tourism sector in mountain destinations.
\end{abstract}

Key words: Amenity migration, mountain tourism destinations, competitiveness, local development.

\footnotetext{
1 El presente trabajo es parte del proyecto de investigación "Migración de amenidad y desarrollo sustentable de destinos turísticos competitivos" del Centro de Estudios para la Planificación y el Desarrollo Sustentable del Turismo-CEPLADES Turismo, dependiente de la Facultad de Turismo de la Universidad Nacional del Comahue, Neuquén, Argen-
}

tina. Artículo recibido el 20 de julio de 2009 y aceptado el 2 de septiembre de 2009.

2 Centro de Estudios para la Planificación y el DesarroIlo Turístico Sustentable (CEPLADES-Turismo), Universidad Nacional del Comahue (Argentina). Email: rgonzale@uncoma.edu.ar; otero@uncoma.edu.ar; lianaka@arnet.com.ar; marioni.susana@speedy.com.ar 
El desarrollo turístico implica distintos tipos de movilidades, sobre todo de personas, objetos y capitales, aunque también involucra la movilización relacional de recuerdos, emociones y diversas puestas en escena. Esta compleja serie de movilidades entrañan una serie de riesgos para las comunidades receptoras en términos de cambios culturales, paisajísticos y medioambientales. La aparente "muerte de las distancias" (Sheller y Urry, 2004: 4) como una de las características esenciales de la modernidad líquida, hace de carácter global las movilidades del turismo. Los destinos turísticos, y en este caso los destinos de montaña, son lugares que se ponen en juego para responder a una oferta global.

Una parte de estas movilidades corresponde a las migraciones de amenidad, que conforman una tendencia social a escala mundial y pueden describirse como la migración de personas desde las grandes metrópolis a ciudades pequeñas o pueblos en el interior, sobre todo destinos de montaña, cuya calidad ambiental y cultural es percibida como superior a la de sus antiguos lugares de residencia. La migración por amenidad es así un agente de cambio global que tiene especial efecto en los parajes rurales o pueblos más pequeños (Glorioso y Moss, 2006). Este fenómeno migratorio es una migración inversa, de la ciudad al campo; los sujetos de este proceso son en muchos casos personas que, habiendo sido turistas en un determinado destino, deciden regresar a él ya no para visitarlo, sino para constituirse en habitantes del mismo (Nakayama et al., 2005).

Los centros turísticos de montaña son destino de migraciones de amenidad en todo el mundo. Son lugares con sus propios significados y asociaciones para sus residentes e incluso sus visitantes, pero también poseedores de una combinación de características que los definen como bellos paisajísticamente, cosmopolitas, exóticos, aunque también degradados social y ambientalmente. Las migraciones de amenidad pueden considerarse en muchos casos como una sombra del desarrollo turístico, ya que el tipo de movilidades que causan podría interpretarse como regresivas en términos de desarrollo local. En el proceso de obtener sus necesarias características cosmopolitas, los destinos de montaña se alistan para reencarnarse en otros lugares donde será posible desarrollar otros juegos; en la mayoría de los casos observados en Argentina, se trata del libre juego del negocio y la especulación inmobiliaria. En estas puestas en juego, y resultado de estas movilidades, los lugares comienzan a ser consumidos a medida que son visitados, unos tras otro, en un proceso continuo de consumo de cuerpos, imágenes, información, hasta que finalmente resultan agotados (Sheller y Urry, 2004). Un riesgo adicional se suma a esta situación y es la posibilidad de que el desarrollo turístico se lleve a cabo en definitiva como una suerte de pantalla de otros tipos de negocios, como se explicitó anteriormente, relacionado con otros intereses vinculados sobre todo con la especulación inmobiliaria. En este sentido, la migración de amenidad representa una amenaza al desarrollo local por su poder para ocultar la falta de competitividad del sector del turismo de muchos de los destinos de montaña.

El objetivo de este trabajo es identificar y analizar una serie de problemáticas y contradicciones derivadas de las movilidades del turismo y el proceso de migración de amenidad en cuatro destinos turísticos de montaña de Argentina, con el fin de promover pautas para diseñar una agenda de manejo de estos procesos que aliente el desarrollo local y la competividad de estos destinos.

\section{Metodología}

El enfoque metodológico utilizado fue predominantemente cualitativo, diacrónico y sincrónico, con base en el análisis de datos secundarios (información demográfica, informes sectoriales y locales) y primarios (entrevistas a actores representativos). El enfoque cualitativo comprendió entrevistas focalizadas a los actores representativos de distintas décadas migratorias y entrevistas en profundidad a nativos de diferentes grupos etarios. Asimismo, se realizaron talleres comunitarios en los cuales se aplicaron técnicas de investigación-acción participativa.

Se seleccionaron como casos de estudio cuatro destinos turísticos de montaña de Ar- 
gentina: San Martín de los Andes (SMA), ViIla La Angostura (VLA), Villa General Belgrano (VGB) y El Bolsón y Lago Puelo (EB-LP) (Figura $\mathrm{N}^{\circ} 1$ ). La elección de estos destinos se realizó priorizando la situación de los mismos en ambientes de montaña (cordillera de los Andes para San Martín de los Andes,
Villa La Angostura y El Bolsón y Sierras Pampeanas para Villa General Belgrano). Entre ellos hay, sin embargo, notables diferencias en su proceso fundacional y en su evolución turística, que inciden sobre el fenómeno de migración de amenidad llevado a cabo en esas comunidades.

Figura $\mathrm{N}^{\circ} 1$

Localización de casos de estudio

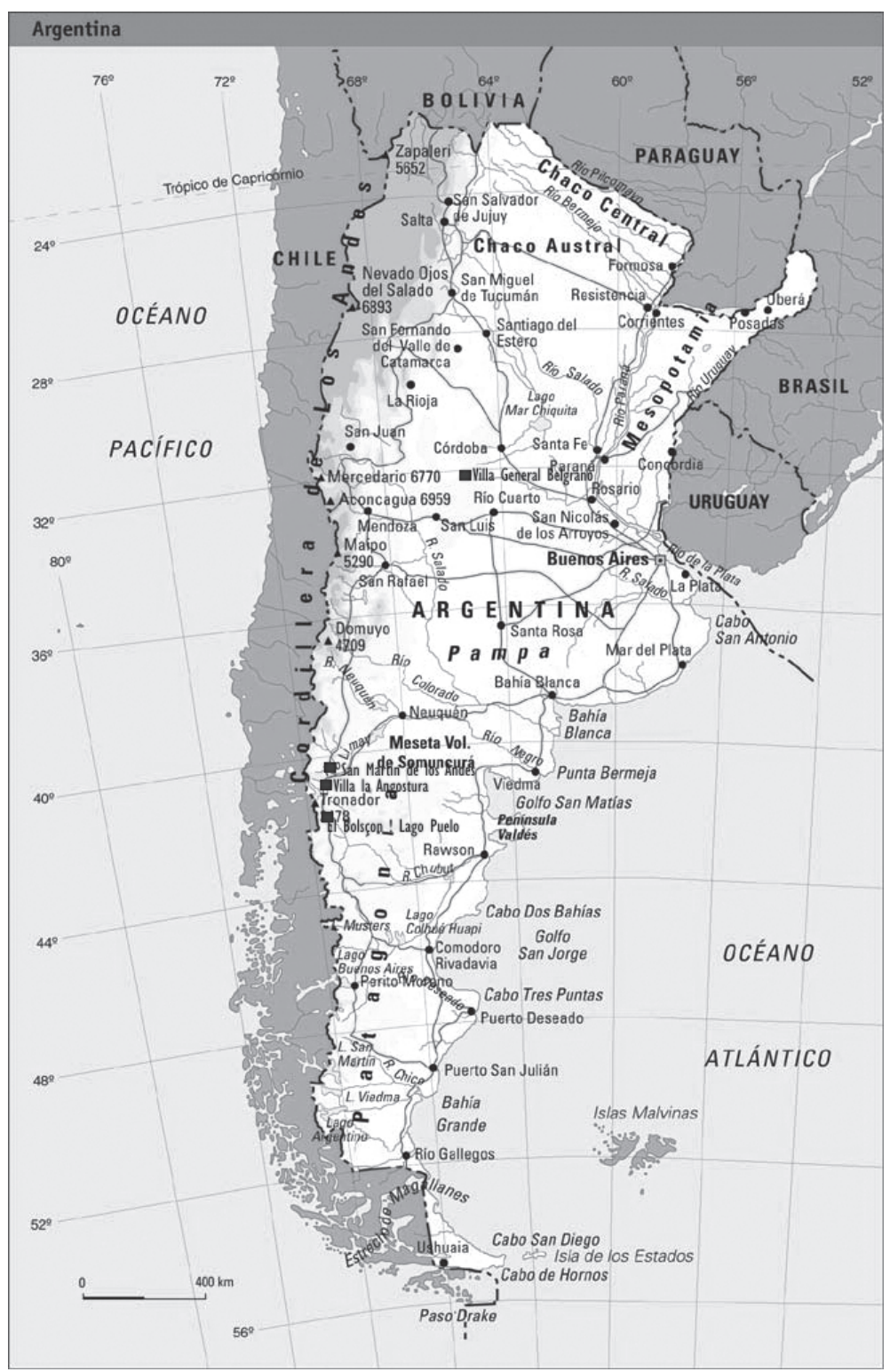

Fuente: Elaboración propia. 
Las personas entrevistadas en cada uno de los casos fueron seleccionadas por informantes clave de cada localidad, elegidos por poseer dos requisitos: larga residencia en el destino y un rol-social o institucional-que les da la oportunidad de conocer con aproximación razonable a todos los habitantes de su ciudad. El criterio para determinar el tamaño de la muestra fue muestreo por juicio, siguiendo el principio de representatividad estructural (Mejía, 2000), en base a lo cual se determinaron listados de posibles entrevistados de acuerdo a los siguientes criterios teóricos: para los nativos, una representatividad mínima de cada grupo etario: 20-30, 31-40, 41-50 y más de 50 años; y para los inmigrantes, década de arribo: hasta 1970, 1971-1981, 19821991, 1992-2001 y 2002 en adelante. Se procuró que el número mínimo de entrevistados de cada grupo o década fuera de cinco. La tarea de campo demandó, en consecuencia, un tiempo relativamente prolongado y pueden haber incidido en forma diferente las circunstancias contextuales (económicas, políticas y sociales) de cada temporada de trabajo.

La información recolectada versó: a) Para los inmigrantes, sobre cómo vivieron los tres momentos del proceso migratorio: decisión, instalación e integración al nuevo destino, y cómo perciben el movimiento migratorio de quienes llegaron después, y b) Para los nativos, sobre cómo recuerdan el pueblo de su niñez y cómo se fue modificando a medida que Ilegaron nuevos pobladores.

El número de entrevistados fue de 126 para SMA (72 en junio de 2006 y 54 en septiembre de 2007), 61 para VGB (tomadas en marzo de 2007), 40 en VLA (tomadas en noviembre de 2007) y 24 en EB-LP (tomadas en marzo de 2008). La información recolectada fue analizada mediante técnicas de análisis de contenido y, en algunos casos, de análisis del discurso, con el fin de comprender el proceso migratorio a través del tiempo y los factores que explican sus relaciones con la gestión del desarrollo turístico del destino.

\section{Caracterización de los casos de estudio}

San Martín de los Andes (SMA) es un pueblo de montaña con una población de alrededor de 22.432 habitantes en 2001 (INDEC, 2001), 51,1\% más que en el año 1991, cuando poseía 14.842 habitantes (INDEC, 1991). Se encuentra en la margen norte del lago Lácar, en el suroeste de la provincia del Neuquén, $420 \mathrm{~km}$ al suroeste de la capital provincial. La ciudad está a 640 m.s.n.m., rodeada por la cordillera de los Andes. San Martín de los Andes es el destino que actúa como puerta de entrada al Parque Nacional Lanín, uno de los lugares favoritos en la Argentina para turistas, recreacionistas y migrantes por amenidad.

Villa La Angostura (VLA) es considerada como uno de los principales atractivos de la Patagonia andina argentina. Se encuentra dentro de Parque Nacional Nahuel Huapi, siendo la puerta de entrada al Parque Nacional Los Arrayanes. Tiene una población de 7.526 (INDEC, 2001), aunque se estima que durante el año 2008 alcanzó los 17.000 habitantes, con una tasa de crecimiento anual del 121,83\% (1991-2001) y una densidad de población de 98 habitantes por $\mathrm{m}^{2}$.

Villa General Belgrano (VGB) se localiza en el centro del valle de Calamuchita, en la provincia de Córdoba, $85 \mathrm{~km}$ al sur de la ciudad capital provincial. Tiene 5.888 habitantes estables (INDEC, 2001). VGB se ha desarrollado como un proyecto de aldea, con una estructura urbana con dirección norte-sur y que se distingue por sus edificios con una arquitectura de estilo característico de Europa central. El incentivo para el desarrollo del turismo se inició a mediados de los años 70; se puede decir que hoy VGB vive casi exclusivamente de las contribuciones de la actividad turística.

El Bolsón y Lago Puelo (EB-LP) son pueblos de montaña ubicados en el sector de la Patagonia conocida como la comarca Andina, en el paralelo 42. La comarca tiene aproximadamente $4.300 \mathrm{~km}^{2}$, está situada en la parte suroeste de la provincia de Río Negro y la sección noroeste de la provincia de Chubut. A pesar de que estos pueblos pertenecen a dos provincias diferentes -Chubut y Río Negro- están territorialmente contiguos, presentando algunas características comunes relacionadas con su similar proceso de desarrollo histórico, compartiendo las tradiciones y hechos culturales, así 
como un proceso análogo de evolución demográfica.

\section{Las movilidades del turismo}

Los lugares no son tales solo por sus propias asociaciones y significados para aquellos que residen e incluso para los que visitan un sitio, sino también por una combinación de características abstractas que los distinguen por su carácter escénico, cosmopolita o exótico. Este lenguaje de características abstractas es el de las movilidades; las del turismo se refieren a las diferentes movilidades que, en la forma de distintas actividades turísticas, terminan dando forma a los lugares donde se desarrolla la actividad y que, en consecuencia, son responsables de la construcción y del desmantelamiento de los destinos turísticos. El desarrollo turístico también involucra movilidades de personas y objetos, de emociones y de ambientes, lo que lleva implícito muchos riesgos para el entorno natural y cultural de las comunidades receptoras.

Las movilidades del turismo no pueden ser analizadas separadas de la consideración de un complejo conjunto de movilidades. Los destinos turísticos solo pueden y deben ser analizados e interpretados como sistemas complejos donde se produce una intersección de múltiples movilidades. El desarrollo turístico construye puestas en escenas que promueven otras movilidades y desmovilizaciones. Por tanto, en los destinos de montaña es dable identificar superposiciones entre las movilidades propias del turismo y aquellas generadas por otras actividades económicas, profesionales, o bien por los propios movimientos migratorios desde y hacia los mismos (Sheller \& Urry, 2004). Los destinos turísticos de montaña, como lugares puestos en juego, pueden ser concebidos como sitios producidos de manera económica, política y cultural, a través de la red de múltiples movilidades de capitales, personas, objetos, signos y de información (SheIler \& Urry, 2004).

El carácter global de las movilidades del turismo implica un movimiento consumista de cuerpos, imágenes e información. Como resultado de estas movilidades, los lugares comienzan a ser consumidos a medida que son visitados o elegidos como nichos de mercado, unos tras otro en un proceso continuo de consumo de cuerpos, imágenes e información, hasta que finalmente resultan agotados en el camino a la necesaria adquisición de características cosmopolitas, donde se alistan para reencarnarse en otros juegos, otros lugares y otras puestas en escena. En muchos casos, estos destinos se convierten en lugares llenos de sentimientos de decepción y frustración, cuando las expectativas de desarrollo personal y las puestas en juego previamente imaginadas no pueden cumplirse (Sheller \& Urry, 2004).

Las movilidades del turismo están siempre localizadas y materializadas. Los lugares para jugar, y por ende los lugares que se ponen en juego, solo se estabilizan de manera contingente a los fines del consumo turístico. Este proceso de estabilización requiere una amplia gama de otras desmovilizaciones y removilizaciones: de trabajo y mano de obra, de capitales, de migrantes y de ciudadanos, así como también de imágenes, de información, de bienes físicos y de realidades virtuales (Sheller \& Urry, 2004).

\section{El fenómeno de las migraciones de amenidad}

La migración se constituye por un número significativo de decisiones individuales que, sumadas, producen efectos importantes en la configuración de la personalidad colectiva de las ciudades destinos. Esas decisiones pueden ser tomadas en forma forzada (caso de los Ilamados refugiados ${ }^{3}$, que son totalmente ajenos a este estudio) o voluntaria. Entre las causas voluntarias, las teorías tradicionales -predominantemente económicas- expresan la función de migración como:

\footnotetext{
3 De acuerdo a la Convención de 1951 (ACNUR, 2007) sobre la situación de refugiados y personas sin país, son personas que: a) Se encuentran fuera de su país de residencia habitual; b) Demuestran un temor fundado de ser perseguidos en razón de su raza, religión, nacionalidad, pertenencia a un determinado grupo social u opinión política; y c) Como consecuencia de lo anterior no quieren o no están en condiciones de requerir la protección de su propio país.
} 


$$
D_{i}=W_{f i}-W_{h i}-Z_{i}-C>0
$$

Donde:

$D_{i}$ : decisión del individuo de migrar.

$\mathrm{W}_{\mathrm{fi}}$ : ingresos de dicho individuo en el país de destino.

$W_{h i}$ : ingresos de dicho individuo en el país de origen.

$Z_{i}$ : diferencial compensador del individuo a favor del origen.

C : el coste directo de la migración.

Este modelo, desarrollado por Hatton y Williamson (2006), es aplicable en los casos en los que la decisión obedece a factores mensurables: mayores salarios, mayor rentabilidad, menor riesgo de desvalorización de activos, entre otros. Pero ¿en qué medida es válido para reconocer el fenómeno a través de factores no mensurables?

La migración de amenidad es un fenómeno de reciente análisis dentro del estudio de las migraciones. Moss (2006) lo define como "la migración llevada a cabo por personas que habiendo sido turistas en un determinado destino, deciden regresar a él ya no para visitarlo, sino para constituirse en habitantes del mismo" (Moss, 2006: 3). Su permanencia puede ser estacional o durante todo el año. Para este autor, alrededor del mundo ha surgido una fuerza económica y social que está proveyendo nuevas oportunidades para las comunidades de montaña, lugares con alta calidad ambiental y características culturales distintivas que son polos de atracción para nuevos residentes.

La definición de Moss (2006) aporta elementos valiosos para identificar condiciones que caracterizan el proceso de migración de amenidad (Nakayama y Marioni, 2007):

- Es migración, en tanto existe un abandono de su lugar de residencia habitual para adoptar otro nuevo.

- Los migrantes fueron antes turistas, que vivenciaron por unos días el ambiente del lugar y decidieron en memoria de esas vivencias.

- Los migrantes se asientan en su nuevo destino con la idea de permanecer.
Los componentes de la definición dan lugar a la existencia de otras características de este fenómeno migratorio:

- La elección del destino recae generalmente sobre una localidad bastante conocida, situada dentro del país (otra localidad de la misma provincia u otra provincia). Son raros los casos de personas que han atravesado el océano para migrar, en esto se diferencian notoriamente de quienes vinieron hacia América en el siglo XIX y primera mitad del siglo XX.

- La elección de una localidad turística connota fuertemente la actividad de los migrantes en el destino: si reciben fondos de sus lugares de origen, viven como si fueran turistas permanentes; si deben generarlos en el lugar de destino, se dedican a actividades relacionadas con el comercio o los servicios turísticos.

- La fortaleza relativa de sus capitales económico y social les permite aspirar a jugar, casi inmediatamente, roles protagónicos en los destinos. Este atributo tiene consecuencias muy significativas en la gestión del desarrollo local, como se verá más adelante.

Además de los factores motivacionales, existen agentes facilitadores claves en este proceso, tales como el aumento de la disponibilidad de tiempo y una riqueza discrecional, el incremento en el acceso a tecnología de información, comunicación y otros sistemas de servicios ahora presentes en áreas anteriormente lejanas, debido a las mejoras en los sistemas de transporte aéreo y terrestre y los avances tecnológicos que permiten nuevas formas de comunicación e información; facilidades públicas, infraestructura y servicios como rutas pavimentadas, agua, electricidad, sistemas de manejo de basura, hospitales, bibliotecas, protección de incendios, entre otros, y demás servicios privados complementarios (Moss, 2006).

Los migrantes por amenidad buscan residencias temporales o permanentes en sitios donde pueden elevar su calidad de vida y son atraídos principalmente por lugares con cualidades medioambientales y culturales propias. Dentro de los factores que motivan 
a estos nuevos residentes a mudarse a localidades de montaña pequeñas pueden destacarse: una fuerte valoración del ambiente natural, diferenciación cultural y ocio, aprendizaje y espiritualidad (Moss, 2006). Williams, Gill y Moore (1993) expresan que "los migrantes de amenidad buscan su residencia permanente o temporal en áreas donde pueden tener fácil acceso a recursos naturales y culturales de mayor calidad que los normalmente disponibles para ellos en sus domicilios anteriores. Atribuyen valor considerable a la presencia de características ambientales protegidas, mientras demandan oportunidades de crecimiento artísticas y culturales, instalaciones distintivas para compras y recreación, servicios de salud de calidad y en algunos casos seleccionan opciones del empleo" (Williams, Gill y Moore, 1993).

The Chinook Institute for Community Stewardships (2005) en una investigación cuyo caso de estudio fue Alberta, Canadá, define que las amenidades que buscan las personas que deciden mudarse a localidades más pequeñas varían de acuerdo a las percepciones y valoraciones que estos hagan en función de sus necesidades; generalmente los aspectos decisivos comprenden un ambiente saludable que incluye aire y agua limpios; entorno de pequeños pueblos, con un tranquilo ritmo de vida, menos tráfico, ruido y una comunidad amigable, más comprensiva y socialmente más cohesiva; bajos impuestos; menos crimen y más seguridad; mejores escuelas; más espacios abiertos; y creciente acceso a oportunidades recreativas en áreas naturales con espacios abiertos y vida silvestre.

También son atractores los valores culturales que estos lugares ofrecen, diferentes a los de los antiguos asentamientos de los nuevos migrantes.

La migración de amenidad tiene como razón principal del desplazamiento la búsqueda de una mejor calidad de vida. Ello obliga a saber qué componentes se consideran necesarios para tenerla o adquirirla; y aunque la expresión calidad es ontológicamente cualitativa, los hallazgos de estudios anteriores aportan indicios que permiten afirmar que lo económico está presente casi siempre en las valoraciones personales ${ }^{4}$, y rara vez una decisión de migrar se toma pese a la desventaja económica del destino.

El modelo de Hatton y Williamson (2006) parece aplicable a la migración de amenidad, pero solo parcialmente: aún no se poseen herramientas metodológicas suficientes para atribuir valores a $Z_{i}$ o a un nuevo factor que podríamos Ilamar (+) $Y_{i}$, que representa el diferencial positivo del individuo a favor del destino (calidad ambiental, valor escénico, percepción de seguridad personal). Con estas modificaciones, la función de migración respondería al siguiente modelo:

$D_{i}=W_{f i}-W_{h i}-Z_{i}+Y_{i}-C>0$

Donde:

$\mathrm{D}_{\mathrm{i}}$ : decisión del individuo de migrar.

$W_{f i}$ : ingresos de dicho individuo en el país de destino.

$W_{h i}$ : ingresos de dicho individuo en el país de origen.

$Z_{i} \quad$ diferencial compensador del individuo a favor del origen.

$Y_{i}$ : diferencial positivo del individuo a favor del destino.

C : coste directo de la migración.

Uno de los impactos más importantes de este tipo de migración es el proceso de fragmentación de la tierra rural para desarrollar modelos de urbanización que se denominan ciudades difusas. Estos modelos separan y fragmentan las distintas funciones de la ciudad, a diferencia de la ciudad histórica o tradicional, caracterizada por su carácter más compacto y diverso. En este nuevo modelo domina un patrón extensivo y autosuficiente, con procesos de fragmentación del suelo, loteos y privatizaciones de los usos de este, hechos que favorecen la prevalencia de un espíritu individualista y poco sustentable (Souto González, 2006).

4 Las declaraciones de los migrantes de amenidad remarcan con firmeza sus motivaciones no económicas, pero ellas se hacen visibles en las actividades que desarrollan en el destino o continúan ejerciéndolas en sus lugares de origen. 


\section{Problemáticas y contradicciones de las movilidades turísticas en el desarrollo local}

\author{
Las contradicciones entre el discurso \\ oficial y las consecuencias negativas de \\ la migración de amenidad en destinos \\ turísticos de montaña
}

En primer término, se puede identificar una contradicción manifiesta entre el discurso oficial de los agentes a cargo del desarroIlo turístico en destinos de montaña, tanto a nivel municipal como provincial, que promueven y fomentan siempre que sea posible la llegada de nuevas inversiones y con ellas la aparición de nuevos migrantes por amenidad como aspectos siempre positivos del desarrollo y los efectos negativos cruciales para estos destinos en términos de su crecimiento social y económico, casi siempre ocultados por las políticas y acciones públicas en la materia.

Aunque no son observables políticas migratorias nacionales o provinciales que alienten efectivamente los procesos migratorios, se reconoce una voluntad favorable de la mayoría de las administraciones gubernamentales hacia el asentamiento de nuevos inmigrantes, a través de instrumentos de fomento, tales como líneas crediticias o políticas de exenciones impositivas.

Moss (2006) menciona la frase "el crecimiento es bueno" (Moss, 2006: 20), como el pensamiento predominante en la mayoría de los destinos turísticos. Cada año se presenta una velada competencia entre destinos para tener la mayor cantidad de crecimiento en metros cuadrados construidos, el mayor número de camas turísticas ofertadas, la mayor cantidad de turistas recibidos y el mayor porcentaje de ocupación, como sinónimo de crecimiento positivo y desarrollo.

A pesar de este discurso positivo y esta visión optimista, una serie de problemas ambientales y sociales vinculados al crecimiento de la población pudieron ser claramente identificados en tres de los destinos analizados.
A partir de entrevistas en profundidad con informantes clave de Villa General Belgrano, se pudieron identificar una serie de dificultades, entre las que pueden mencionarse la falta de estado de conservación de los cursos de agua que atraviesan el pueblo por la presencia de elementos contaminantes, inequidad social en el acceso a la educación y los servicios de salud, insuficiencia en la infraestructura de servicios, aumento del precio de la vivienda residencial y, por ende, aumento del costo de vida. También se identificó un debilitamiento de los vínculos entre los sectores público y privado; falta de cumplimiento de normativas medioambientales, tanto a nivel provincial como municipal; aumento de la contaminación visual y carencia de servicios recreativos para los residentes.

En San Martín de los Andes (Figura No2) los residentes entrevistados expresaron sus principales problemas: el crecimiento exagerado de la construcción de viviendas y una notable reducción del acceso público a los recursos comunes, aumentando la sensación de problemas relacionados con la marginación y la pobreza: alcoholismo, drogadicción y violencia familiar.

En Villa La Angostura, del análisis de las entrevistas se desprende un aumento sostenido del valor de los bienes raíces, al tiempo que cierta debilidad institucional mostrada por las administraciones reguladoras oficiales pone de manifiesto el problema del acceso a los recursos comunes, una cuestión central en el desarrollo de estos pueblos de montaña. Entre las principales consecuencias pueden destacarse la pérdida del bosque nativo, el aumento de los niveles de contaminación del agua y una desmovilización de pobladores tanto física como social y económica, como se explicitará mas adelante.

El Estado alienta el proceso de desarrollo basado en la visión de la función macroeconómica en donde -al menos teóricamentelos niveles de inversión más altos se corresponden con mayor nivel de productividad, mayor generación de ingresos $y$, por ende, también con tasas de empleo superiores. El problema de este razonamiento es que el tipo de inversiones que desembarca en estos 
destinos de montaña no constituyen siempre fuentes de empleo genuinas, ni son válidas para proteger los recursos comunes de estos destinos. Villa La Angostura puede ser citada como ejemplo paradigmático de estos procesos de falta de competitividad económica que están afrontando la mayoría de los destinos turísticos de montaña (cada uno con sus particularidades), incluidos en el corredor.

La actividad turística, considerada el motor de la economía de estos destinos y en particular de Villa La Angostura, está experimentado síntomas de decrecimiento en varios de sus indicadores. A la tradicional estacionalidad del destino se suma una caída en la rentabilidad del negocio turístico, derivado de una disminución progresiva en los porcentajes de ocupación de los establecimientos hoteleros y extrahoteleros, aun en la paradoja de un crecimiento continuo del número de turistas arribados y de la cantidad de pernoctes registrados.

La ocupación anual promedio de su planta de alojamiento no supera el $40 \%$-de hecho, ningún destino del corredor de los lagos supera ese porcentaje anual-, lo que ya habla de una situación crítica en cuanto a la rentabilidad del sector turístico. Según datos aportados por el Plan Estratégico de Villa La Angostura 2016, y en relación a la capacidad del sector turismo para generar empleo, la envergadura de los establecimientos, que en promedio no superan las 28 plazas y los condicionantes impuestos por la alta estacionalidad, no favorecen la regularidad del nivel de empleo y su calificación dentro del rubro alojamiento. En consecuencia, el nivel de empleo a partir de la actividad turística es muy bajo, con variaciones de acuerdo a la temporada, entre el $42,3 \%$ y el $61 \%$ de los establecimientos tienen uno o ningún empleado y entre el 30,9\% y el $42,3 \%$ tienen entre dos y cinco empleados, y solo entre el $8,1 \%$ y el $15,4 \%$ tiene más de cinco empleados. Además, se presenta la paradoja que a pesar de registrarse prácticamente una duplicación de la cantidad de pernoctes registrados (260.315 en 2002 a 400.335 en 2006) y de turistas alojados (67.753 en 2002 a 80.067 en 2006), también fue notorio el descenso del porcentaje de ocupación en la Villa de la temporada alta invernal en el período 2004-2006, de

Figura $\mathrm{N}^{\circ} 2$

San Martín de los Andes

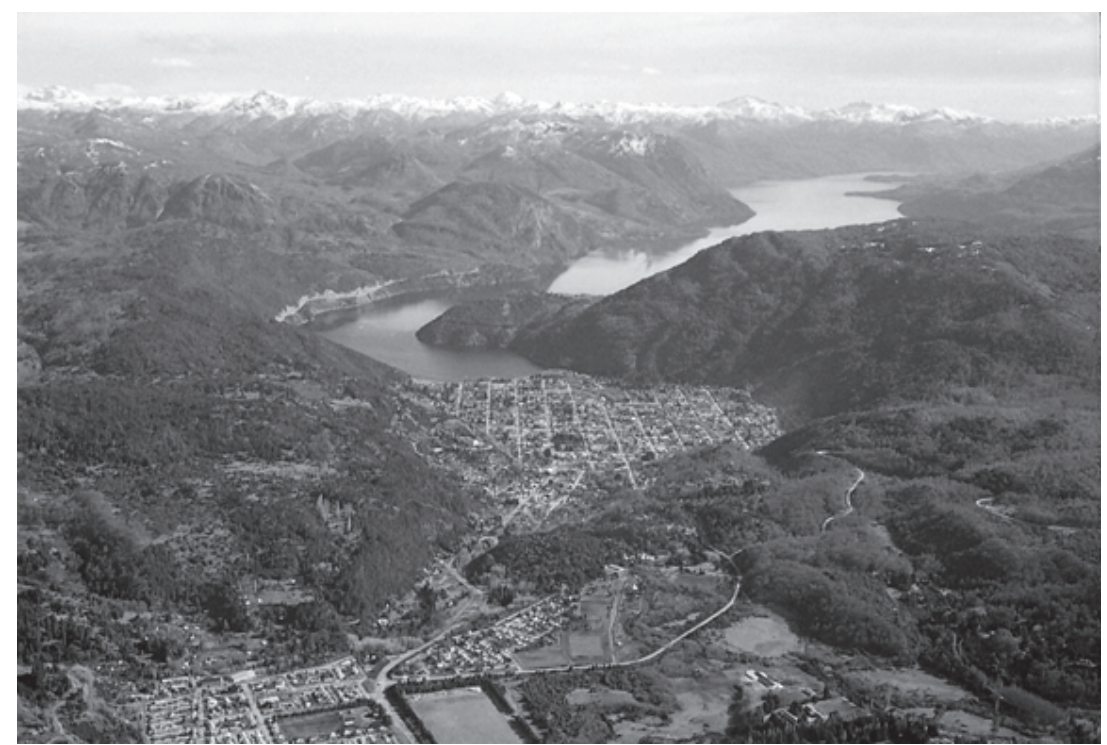

Fuente: Colección personal de los autores. 
$54,37 \%$ a $30,35 \%$ para el mes de julio y de $34,9 \%$ a $29,66 \%$ para el mes de agosto del mismo período. Así, el disparador de la competitividad de cualquier destino turístico, la rentabilidad de las inversiones, sigue estando en jaque, porque la oferta supera claramente a la demanda, aun en una situación de crecimiento sostenido de esta última.

La explicación de esta situación es una clara sobredimensión de la oferta frente a la demanda turística, resultado de una "burbuja de crecimiento exógeno" (Landriscini, 2008: 16), que atrajo inversiones orientadas a la construcción de emprendimientos hoteleros que hoy no son rentables, con baja generación de empleo y de carácter estacional, en función de tratarse de empresas familiares. Todo esto redunda en una situación de precarización laboral y de reducción progresiva de los ingresos de los trabajadores, muchos de los cuales se sintieron atraídos por la promesa de un futuro laboral floreciente en el sector que hoy en día ya no es tal. El resultado es el gradual empobrecimiento de un importante sector de la comunidad conformado por trabajadores cuentapropistas, estacionales, pequeños comerciantes y prestadores de servicios, así como antiguos residentes (Figura $\mathrm{N}^{\circ} 3$ ).

Esta primera contradicción deja ver una serie de problemas comunes de muchos destinos de montaña donde se desarrollan procesos de migración de amenidad y donde el ejercicio del poder es muy complejo, atrayendo a una diversidad de flujos de intere- ses y de personas, turistas, migrantes y trabajadores con un espectro de necesidades muy diferentes. Se suma a esto la falta de visión del Estado para proporcionar una situación de bienestar en términos de la utilización equitativa de los recursos comunes. En primer lugar, hay que reconocer que todavía es muy difícil de diseñar e implementar políticas que limitan el crecimiento en Argentina; en general, los valores que prevalecen en la arena política están relacionados principalmente con crear y mantener la gobernabilidad y, como un balance necesario, la eficacia presupuestaria. En este marco, intentar frenar o limitar el crecimiento urbano puede dar lugar a costos políticos altos, inaceptables en términos electorales.

La naturalización de las desigualdades sociales y económicas de muchos de los destinos turísticos de montaña en Argentina se produce, entre otros factores, en parte debido a la corrupción administrativa y económica de los gestores locales, así como de la falta de gestión pública y participación de los interesados en los asuntos públicos. El esquema se completa con la eterna discontinuidad de las políticas turísticas a mediano y largo plazo. Es claramente un problema de las instituciones del Estado, que se muestran incapaces de regular un aspecto clave del turismo: el desarrollo de la oferta turística y su cercana relación con el negocio inmobiliario.

\section{EI "efecto espejo" y la ciudad difusa}

La segunda contradicción se relaciona con la imagen que los destinos de montaña

Figura $N^{\circ} 3$

Inversiones en emprendimientos hoteleros

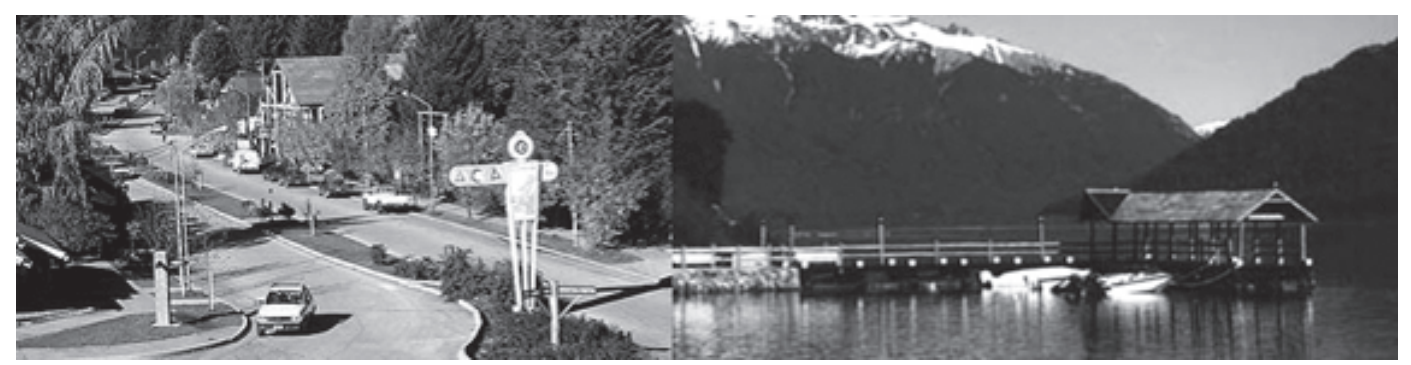

Fuente: Colección personal de los autores. 
proyectan en los turistas y en los habitantes de las grandes ciudades y las consecuencias que tiene posteriormente esa imagen en la conducta de los migrantes por amenidad, una vez que se trasladan a estos lugares y se convierten en sus nuevos residentes.

Los migrantes se desplazan a las áreas de montaña motivados por una imagen idílica que han ido construyendo respecto de esos espacios, pero llevando con ellos rezagos activos de su anterior vida citadina. Esto termina conformando lo que puede denominarse como "efecto espejo": la reproducción del antiguo modo de vida urbano, pero ahora dentro de un ambiente de montaña. Las imágenes, valores y formas sociales vividas y sentidas una vez en la ciudad, están destinados ahora a ser reproducidos en el nuevo entorno. Muchas de las condiciones que facilitaban y hacían viable la vida en la ciudad comienzan a ser necesitadas y requeridas por los migrantes por amenidad, pero esta vez ya en su nuevo lugar en las montañas. Los nuevos migrantes se resisten a perder estos beneficios que alguna vez fueron proporcionados por las grandes ciudades y de variadas maneras comienzan a ejercer una suerte de presión sobre los recursos locales, en busca de condiciones de confort y calidad de vida que incluyen disponibilidad de recursos tecnológicos, condiciones y equipamiento de seguridad, facilidades y servicios recreativos y acceso a niveles elevados de educación formal.

De acuerdo a Urry (2004), cada vez hay más similitudes entre las conductas en casa y fuera. Hay un hecho que los administradores de estos destinos deben poder reconocer y entender: estas nuevas inversiones que Ilegan a las comunidades de montaña son, en realidad y en la mayoría de los casos analizados, formas de respuestas a esas exigencias de estos nuevos habitantes. Uno de los primeros requerimientos se relaciona obviamente con la vivienda. Los migrantes buscan reproducir también en este aspecto su anterior vida urbana, aunque ahora en las montañas; el resultado es una búsqueda consumista de territorios, donde se desarroIla este "efecto espejo". Comienza a plasmarse entonces un nuevo modelo de ciudad difusa, que va dando lugar a nuevas formas urbanas.
En este nuevo modelo, consumista también en términos territoriales, la idea de un centro de la ciudad desaparece y en su lugar aflora una sucesión de espacios anónimos. Genéricamente, son lugares que conforman sistemas morfológica y funcionalmente aislados; lugares sin historia y, por tanto, carentes del sentido de pertenencia. En definitiva, y en los términos de Auge (1992), son no lugares. Son espacios con servicios urbanos de baja calidad, baja densidad de población y muy débiles vínculos con el medio ambiente urbano. Son también lugares de nuevos conflictos y nuevas formas de interacciones sociales.

La proliferación de este modelo de ciudad difusa es uno de los cambios más significativos que se pueden ver en el nuevo entorno urbano de los destinos de montaña de Argentina hoy en día. La "countrización" ha alcanzado ya a muchos de ellos, y a los espacios que los circundan, donde no es difícil observar conjuntos de estos barrios cerrados, que ofrecen las condiciones de seguridad y aislamiento necesarios para estos nuevos migrantes cosmopolitas. Estos distritos son un fenómeno nacido en las grandes ciudades en las últimas dos décadas, debido, entre otros aspectos, a la creciente sensación de inseguridad y la necesidad de nuevos espacios abiertos y fomentados por el mercado inmobiliario. Nan Ellin (2003) señala que "...protegerse del peligro fue uno de los incentivos principales para la construcción de ciudades. Sin embargo, de ser un lugar seguro, la ciudad ha pasado a ser más habitualmente relacionado con el peligro que con la seguridad, sobre todo en los últimos cien años. Debido a una curiosa inversión de su papel histórico, y en un claro desafío a sus intenciones y expectativas originales, nuestras ciudades distan de ser un refugio frente a los peligros y se están convirtiendo en la principal fuente de estos..." (Ellin, 2003: 43-61). En el mismo sentido, Bauman (2006) sostiene que "...las fuentes de peligro se han trasladado al corazón mismo de las ciudades. La guerra contra la inseguridad, los peligros y los riesgos, se libra ahora en su interior y es dentro de ella donde se definen los campos de batalla y se trazan las líneas de frente. Las trincheras y los bunkers, fuertemente blindados y cuya finalidad original era la de separarse 
de los extraños manteniéndolos alejados y vedando su entrada, están pasando rápidamente a ser uno de los aspectos más visibles de las ciudades contemporáneas, si bien las formas que adoptan son muy numerosas y sus diseñadores se esfuerzan por mezclar sus creaciones con el paisaje urbano, lo que contribuye a "normalizar" el estado de emergencia en el que viven los habitantes urbanos, adictos a la seguridad..." (Bauman, 2006: 99).

El desarrollo de estas formas de nuevas ciudades difusas requiere la disponibilidad de grandes espacios abiertos. Agotados los espacios disponibles en las grandes ciudades, comienza una búsqueda de conquista de nuevos territorios a nivel nacional, pero también global, y está de moda poner la mira en las áreas de montaña. Los destinos turísticos de montaña suelen considerarse la primera oportunidad atractiva para planificar y construir nuevas ciudades difusas. El caso más representativo de este fenómeno y que ejemplifica esta proliferación de ciudades difusas es Villa La Angostura. Esta villa de montaña está viviendo un boom inmobiliario desde la crisis de 2001, cuando muchas personas deciden invertir en el sector de la construcción. A partir de entonces, los índices de construcción no han cesado de incrementarse, acompañados por el aumento sostenido de los costos de la construcción y del valor de la tierra. Durante 2004 y 2005, por ejemplo, las tierras con mayores valores comerciales fueron las situadas cerca de la orilla del lago y en las riberas de los ríos, o las que tienen una vista directa a las montañas o al lago; solo en ese período su precio creció hasta un 50\%. Muchos de estos desarrollos se ofertan y promocionan como barrios de montaña y se instalan usualmente en lugares con alto riesgo ambiental, como costas de lago y laderas montañosas.

Villa General Belgrano (Figura No 4) está viviendo un fenómeno similar, que tiene lugar en sus zonas aledañas, simplemente porque ya no hay espacio disponible dentro de los límites del pueblo. El fenómeno se ha expandido a las pequeñas comunidades ve-

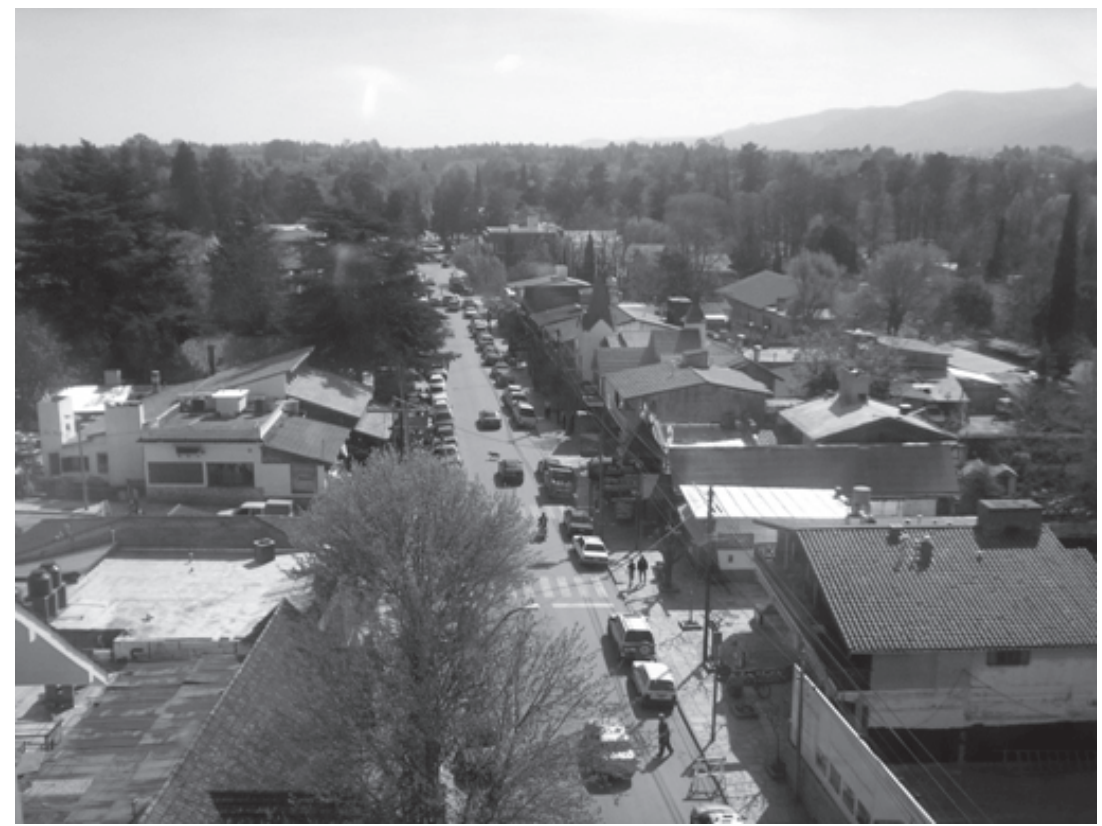

Fuente: Colección personal de los autores. 
cinas, que se enfrentan ahora a nuevos desarrollos sobre la base del mismo patrón: la subdivisión de la tierra para la construcción de nuevos barrios cerrados, bajo las denominaciones de countries y villas o barrios de montaña, llevados a cabo por agentes inmobiliarios fundamentalmente de Córdoba capital, situada a solo $85 \mathrm{~km}$ al norte de Villa General Belgrano.

En San Martín de los Andes la falta de disponibilidad de espacio es una grave preocupación. Rodeado de laderas de montañas, el pueblo simplemente no puede continuar creciendo más dentro de sus límites. Sin embargo, y en respuesta a exigencias de nuevos migrantes y turistas, $y$ alentado $y$ presionado por agentes de bienes raíces locales y de Buenos Aires, se han desarrollado en los últimos años una serie de instalaciones deportivas y recreativas para segmentos con alto poder adquisitivo. Un ejemplo representativo es el diseño y la construcción de un campo de golf de 18 hoyos diseñado por Jack Nicklaus, solo 5 kilómetros fuera de los límites de la ciudad, formando parte de un emprendimiento que incluye 432 lotes que circundan el campo de golf y el de polo, en un predio de 226 hectáreas, que incluye además un hotel 5 estrellas de 83 habitaciones.

Estas formas de ciudad difusa que, como una avanzada territorial, van ganando más y más terreno en nuestros destinos de montaña, acaban conformando un tipo de remedio contra los efectos de la polarización de la sociedad. Se comienza a revelar la necesidad oculta de protegerse contra la proliferación de pobres. Esta situación pone sobre el tapete la discusión del problema estructural de inequidad de América Latina en general y Argentina en particular. El problema tiene su traducción en el ámbito del turismo, a través de la puesta en venta de la ilusión de vivir en un país desarrollado, a costa de la fragmentación territorial, social y económica de estos destinos.

El turismo es así la puesta en escena para la operación de las fuerzas de la especulación inmobiliaria, conformando la última etapa de una larga lista de reapropiaciones simbólicas del territorio (Dachary y Arnaiz, 2006). Muchas veces quienes absolutizan la utilidad mercantil de un territorio suelen desentenderse de los sentidos acumulados en esa historia de usos, o a veces solo se rescata una época y se desprecian otras, según las posibilidades de ser efectivos en la construcción de la marca del destino.

\section{Los migrantes de amenidad como empresarios turísticos}

Muchos migrantes por amenidad, atraídos por el paisaje y la calidad de vida de los destinos turísticos de montaña, deciden radicarse en estos sitios y en ellos convertirse en empresarios prestadores de servicios turísticos. Una vez en ese rol no pueden alcanzar estándares mínimos de calidad en sus prestaciones. Esta situación se observó particularmente en la comarca de El Bolsón y Lago Puelo (Figuras $N^{\circ} 5$ y $N^{\circ}$ 6). Aquí, el proceso de migración puede ser señalado como causa y consecuencia de diferentes situaciones problemáticas, compartidas con otros destinos de montaña en los Andes patagónicos: crecimiento poblacional con expansión urbana espontánea y confusa, carencia de una normativa explícita y efectiva sobre el uso del territorio, inversión y especulación inmobiliaria orgánica de alcance local nacional e internacional y ausencia de un congruente perfil cultural y socioeconómico.

Puede observarse una correlación positiva entre el incremento en la cantidad de migrantes llegados a la comarca andina y la aparición de nuevas micro y pequeñas empresas turísticas. La mayoría de estos nuevos residentes están directa o indirectamente vinculados con el sector turismo. Buena parte de estas nuevas empresas son pequeños complejos de alojamiento. En los últimos 16 años el servicio de alojamiento ha evolucionado en El Bolsón de 8 microempresas en 1991 a 51 contabilizadas en 2006, lo que significa una tasa de crecimiento del $538 \%$. En Lago Puelo, pudo registrarse una variación desde 23 establecimientos en 2000 hasta 41 en 2007, representando una tasa de crecimiento del 78\% (Marchissio, 2007). Esto se debe en parte a la existencia de barreras bajas de entrada. Resulta relativamente fácil y accesible para los nuevos migrantes ver en el turismo una oportunidad de bajo costo de inversión, ya que los montos 
de capital requeridos en este tipo de inversiones usualmente son significativamente menores que en otros sectores productivos, o que en el mismo sector en otros destinos turísticos de montaña en la Patagonia. Además, actualmente la política gubernamental en relación al crecimiento de la oferta de servicios turísticos no presenta restricciones para la creación de nuevas empresas. Las microempresas turísticas pueden ser fácilmente creadas y puestas en funcionamiento, debido a lo expuesto precedentemente sobre el bajo costo de inversión y a la posibilidad de combinar la actividad turística comercial con tareas familiares.

Este contexto positivo significa una oportunidad para los migrantes, que buscan comodidades para una forma alternativa de vida basada en una mejora de las economías familiares. Por otra parte, el turismo, y espe- cíficamente el sector de alojamiento, es visto por estos nuevos empresarios como una actividad que, en el contexto de la región de los Andes patagónicos, no requiere en principio conocimientos técnicos ni jurídicos. Todos estos factores promueven en los nuevos inmigrantes el sueño de vivir obteniendo ingresos del sector turístico, en un plazo relativamente corto. Estos empresarios no suelen tener una visión de mejorar su posición en el mercado, sino más bien una mera lógica de subsistencia, donde el pensamiento estratégico no es parte del capital social de la empresa. El proceso de toma de decisiones se basa en suposiciones y apreciaciones surgidas muchas veces a partir de las necesidades y visiones personales de los empresarios, pero sin una necesaria visión estratégica que se enfoque al necesario entendimiento de las condiciones de competitividad sustentable del destino donde se asientan.

Figura $\mathrm{N}^{0} 5$

Comarca de El Bolsón y Lago Puelo

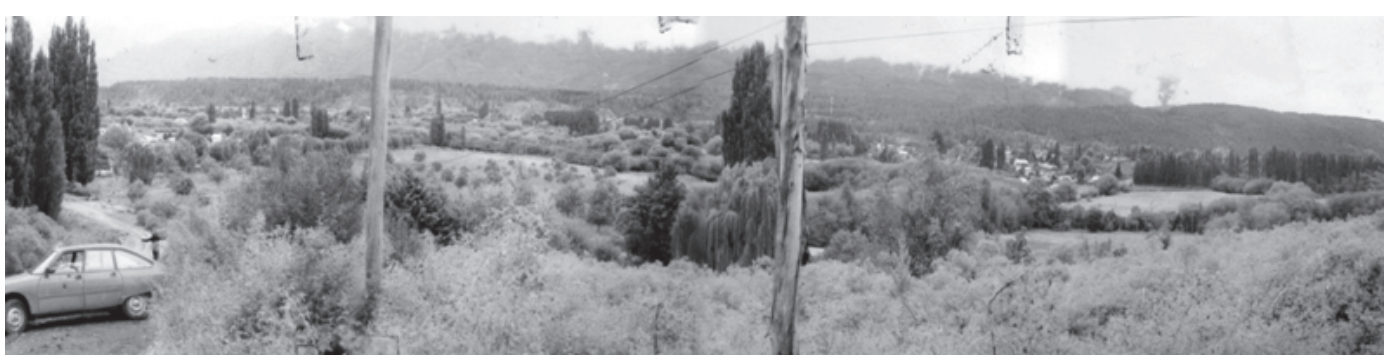

Fuente: Colección personal de los autores.

Figura $\mathrm{N}^{\circ} 6$

Comarca de El Bolsón y Lago Puelo

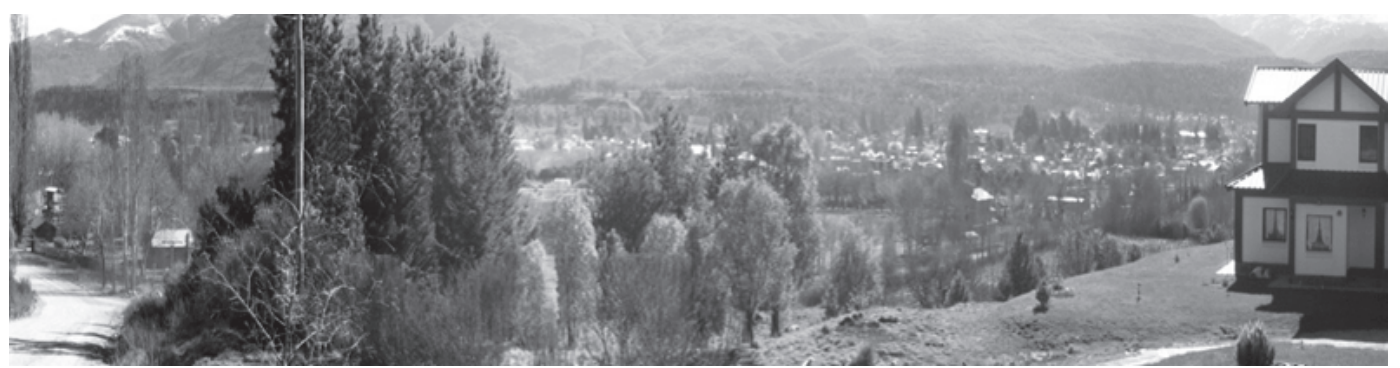

Fuente: Colección personal de los autores. 


\section{Los desplazamientos y la sombra del turismo}

Los destinos turísticos de montaña, en tanto lugares en juego y para jugar, son siempre también lugares para trabajar y para habitar. Tanto el mercado turístico como el laboral generan patrones de migración laboral y formas residenciales transnacionales que deben ser analizadas en conjunto con las movilidades del turismo. Las formas de desapego con un lugar o desterritorialización asociadas con la noción de modernidad líquida -o capitalismo light en términos de Bauman (2006)- siempre están acompañadas por nuevos apegos y reterritorializaciones de naturaleza diversa. Los movimientos de personas, como migrantes, trabajadores, e inclusive como turistas, implican también el movimiento y traslado de equipajes físicos, mapas mentales y muy diversos esquemas culturales.

Mientras que los turistas y los migrantes por amenidad disfrutan de los beneficios de estas movilidades, los residentes comienzan a experimentar desmovilizaciones de diverso tipo. Estos desplazamientos son en primera instancia físicos: los antiguos pobladores comienzan a ser desplazados a nuevas áreas periféricas, perdiendo el acceso a zonas como el centro de las ciudades y riberas de ríos y costas de lagos. Los pobladores son desplazados del acceso a estos recursos comunes, que comienzan a ofrecerse a nuevos grupos de turistas y grupos de poder económico encarnados en nuevos inversionistas, muchos de ellos migrantes por amenidad. A medida que se desarrolla este proceso de desmovilizaciones, comienzan también a darse, como regla general, desplazamientos de carácter social, económico e incluso de naturaleza psicológica de los antiguos residentes. Los mejores lugares, las mejores oportunidades y hasta los puestos de decisión y poder son progresivamente ocupados por nuevos migrantes o por nuevos grupos inversores foráneos. También son observables desplazamientos en el sector laboral, quedando para los residentes los puestos de trabajo operativos, incluyendo tareas de limpieza, de cocina, como proveedores en entretenimientos, ofreciendo sus conocimientos como guías turísticos, choferes y, en el peor de los casos, también la prostitución.
Aunque generalmente la relación entre los residentes y los nuevos migrantes es siempre en principio positiva, debido entre otros aspectos a la necesidad de resolver problemas comunes en la gestión comunitaria del pueblo, a medida que avanza este proceso de migración comienza a hacerse evidente y a ampliarse la brecha entre quienes tienen mayores ingresos y los de menor nivel socioeconómico. Este hecho comienza a dificultar la participación comunitaria en la gestión de los recursos comunes. Este desplazamiento físico y social puede ejemplificarse con el alto porcentaje de respuestas favorables a las solicitudes de exenciones a las normas relativas a planificación del uso del suelo, de construcción y de regulación del uso público de los recursos comunes, a favor de nuevos intereses privados.

El desplazamiento de los aspectos de gobierno y de los procesos de participación popular es claramente percibido por los residentes de San Martín de los Andes y Villa La Angostura: solo una pequeña minoría de los entrevistados residentes en SMA han participado en algún tipo de gobierno local, y los que no lo han hecho, tampoco expresan ganas o intenciones de hacerlo. En Villa La Angostura, los residentes entrevistados señalaron que la diferenciación social se percibe fácilmente en el pueblo; casi la mitad de la población ha sido desplazada, con el advenimiento de nuevos migrantes por amenidad y el consiguiente aumento de inversiones y proyectos foráneos, hacia zonas menos aptas para el asentamiento, con baja densidad de los servicios públicos y con mayores riesgos medioambientales, como las laderas de los cerros que circundan la villa. En correlato, las minorías con mayores ingresos progresivamente van apropiándose de muchos de los antiguos espacios públicos, como las riberas de los ríos y costas de lagos, en incluso algunas calles públicas, en nombre de nuevos proyectos turísticos y en gran parte amparados en ese discurso oficial que ve en el progreso una siempre apropiada ecuación donde crecimiento, a cualquier costo, significa desarrollo, y sobre todo, crédito político.

En todos los casos analizados en este trabajo, el turismo puede ser considerado como un benefactor de los bienes raíces, con gran fuerza de especulación. Tal vez no 
es el turismo en sí, sino lo que puede denominarse la sombra del turismo, ocultando los intereses extranjeros, que promuevan una larga lista de nuevos apropiamientos territoriales, simbólicos y físicos.

El turismo implica la personificación de unas puestas en escena en las que las movilidades no son una liberación o escape de formas identitarias más o menos estables, sino más bien la reproducción y el refuerzo de inequidades, al promover una reiteración y profundización de la fragmentación social de los lugares puestos en juego. En el mismo sentido, también es la puesta en escena de fuerzas de especulación inmobiliaria, que encuentran en el turismo un adecuado pretexto para desarrollar operaciones mercantiles que promueven y que son su verdadero interés.

Alguna vez se discutía si el ocio es la antítesis de la vida cotidiana; hoy nos preguntamos si la migración de amenidad no significa la reconstrucción ociosa de la vida cotidiana. Donde todo lo que se creía irreal y temporario se ha convertido en permanente hasta cuestionar la realidad misma y entender que un territorio terciarizado residencial de alto poder adquisitivo no constituye un modelo apto como territorio de vida; en la medida que genera homogeneización, exclusión, privación del uso de los bienes públicos comunes y promueve la falta de interacción social de sus habitantes.

Más que una distinción binaria entre movilidades globales e inmovilidades locales, las movilidades globales del turismo ocurren gracias a la movilización de locaciones y la renegociación de la materialización de los lugares. Los lugares para jugar son estabilizados solo de manera contingente a los fines del consumo turístico; estas estabilizaciones requieren de una serie de desmovilizaciones y desplazamientos, de trabajo y de capital, de migrantes y ciudadanos, de imagen e información, de equipamientos físicos y realidades virtuales. Por eso, los lugares para jugar son siempre, y de manera global, fluidos, relacionales, $y$, sobre todo, inestables (Sheller \& Urry, 2004).

Sheller (2004), refiriéndose a las islas del Caribe como lugares en juego, estable- ce que quizás el turismo esté situado en contextos de legados postcoloniales, no solo en el Caribe, sino en muchos otros lugares del mundo. Estos lugares son, se piensa, los que se ponen en juego cuando se producen las movilidades del turismo; lugares que continuamente son reinventados, reespecializados y removilizados a través de una estructura narrativa postcolonial, de marcos jurídicos postcoloniales, y también a través de esquemas de gobiernos postcoloniales. ¿No es esta la situación de nuestros destinos turísticos de montaña?

\section{Consideraciones finales}

El Estado tiene un rol indelegable en la definición de un ritmo y un patrón de crecimiento sostenible. Para ello no debe soslayarse su función de proveedor de bienes públicos, de mecanismos de protección y desarrollo social y de creador de condiciones institucionales para un desarrollo más incluyente y equitativo. Apuntando a una efectiva adopción y aplicación de estas políticas, se proponen una serie de pasos para el establecimiento de una agenda para la gestión del crecimiento en los destinos turísticos de montaña de Argentina.

\section{La agenda}

El primer paso es comenzar a definir una agenda para la gestión del proceso de migración de amenidad y el crecimiento de los destinos turísticos de montaña. Para ello se requiere que los gobiernos locales se familiaricen con las necesidades de las comunidades de montaña en relación con los nuevos migrantes, pero también con el fenómeno que se genera al resguardo de la llamada sombra del turismo: la especulación inmobiliaria.

Además se necesita una adecuada comprensión de la estructura de la economía local y nacional y de la naturaleza de las relaciones con los principales mercados regionales y mundiales; junto al fomento de parte del gobierno de capacidades locales y mecanismos de rendición de cuentas, que permitan mejorar la efectividad de las insti- 
tuciones públicas en la prestación de bienes y servicios públicos y el acceso a recursos comunes.

Finalmente, se requiere una diversidad de actores locales efectivamente involucrados, que deberán entender e internalizar que un cambio institucional es necesario. Los gobiernos deben garantizar que el crecimiento puede ser positivo para la comunidad en su conjunto y no solo para beneficio de una minoría en términos de capital económico. Las organizaciones del tercer sector deben a su vez ser conscientes de la importancia de tal cambio y empezar a participar de forma activa en este proceso.

\section{La formulación de políticas}

Las políticas deben estar dirigidas principalmente al desarrollo de estrategias de gestión del crecimiento a escala local, con la participación de todos los agentes locales, prestando especial atención a las necesidades de la población, los recursos naturales y culturales del destino y su entorno.

Deben apuntar también a la creación de un contexto favorable para un desarrollo turístico sustentable, a través de la aplicación de estrategias y procedimientos de mejora de la calidad y de políticas públicas enfocadas en la porción de la competitividad de los microemprendimientos turísticos del destino.

Por su parte, deben ser capaces de permitir una revisión crítica de las normativas y reglamentaciones locales en relación al ordenamiento territorial y el cuidado de los recursos comunes y poner especial atención en el trabajo cooperativo entre las cámaras de comercio, asociaciones locales y organizaciones de tercer sector y los gobiernos locales, enfocados en el desarrollo de estrategias orientadas a la gestión de los procesos de migración de amenidad.

\section{La aplicación}

La aplicación de políticas de gestión de procesos de migración por amenidad y crecimiento de destinos en áreas de montaña en Argentina podría enfrentarse en un contexto con el control y la legitimidad de las instituciones del Estado; las autoridades es- tatales y los sistemas deben ser fuertes y consideradas como legítimas, de modo de permitir la estabilidad de las políticas.

Además, se requiere un servicio público poderoso, competente, autónomo y estable. Los estamentos burocráticos deben existir para crear, dirigir y gestionar un desarrollo económico y social equitativo. También es necesaria la participación activa de redes que promuevan e implementen políticas económicas y sociales

También, se necesita un contexto de prioridades políticas; el gobierno debe promover ese desarrollo económico y social equitativo a través de la priorización de políticas de porción de la capacidad emprendedora y de generación y fomento de microemprendimientos, base de las economías locales.

Respecto de los valores y actitudes locales, el ámbito local es un espacio de generación de innovaciones tecnológicas y sociales, por tanto deberían recrearse los espacios colaborativos para poder adaptarse a los cambios globales e intentar solucionar los problemas propios de estas comunidades. La tolerancia, la meritocracia, la movilidad social y la posibilidad de acceso a crecientes niveles educativos deberían ser valores a promover activamente en estas comunidades.

Finalmente, en cuanto a liderazgo comunitario, la promoción de líderes locales hace posible el desarrollo a escala humana y restringe y limita los niveles de corrupción, por lo que deben fomentarse programas de desarrollo de liderazgo comunitario para estos destinos.

\section{Referencias bibliográficas}

\author{
ALTO COMISIONADO DE LAS \\ NACIONES UNIDAS PARA LOS \\ REFUGIADOS (ACNUR). La Convención \\ 1951 sobre el estatuto de los refugiados. \\ Preguntas y respuestas. Ginebra: ACNUR, \\ 2007. Disponible en Internet: www.acnur. \\ org/biblioteca/pdf/5754.pdf
}

AUGE, M. Los no lugares, espacios del anonimato. Una antropología de la 
sobremodernidad. Barcelona: Editorial Gedisa, 1992.

BAUMAN, Z. Vida líquida. Barcelona: Ediciones Paidós Ibérica, 2006.

DACHARY, A. y ARNAIZ, S. M. Territorio y turismo. Nuevas dimensiones y acciones. Puerto Vallarta: Universidad de Guadalajara, Editorial Pandora, 2006.

ELLIN, N. Fear and the city building. Hedgehog Review, 2003, vol. 5, № 5, p. 43-61.

GLORIOSO, R. \& MOSS, L. Santa Fe, a fading dream: 1986 profile and 2005 prospect. In: MOSS, L. The amenity migrants. Seeking and sustaining mountains and their cultures. Trowbridge: Cromwell Press, 2006, p. 73-93.

HATTON, T. \& WILLIAMSON, J. Global migration and the world economy: two centuries of policy and performance. Cambridge: MIT Press, 2006.

INSTITUTO NACIONAL DE ESTADÍSTICAS Y CENSOS (INDEC). Censo Nacional de Población y Viviendas 1991. Buenos Aires: INDEC, 1991.

INSTITUTO NACIONAL DE ESTADÍSTICAS Y CENSOS (INDEC). Censo Nacional de Población Hogares y Vivienda 2001. Buenos Aires: INDEC, 2001.

LANDRISCINI, G. Dinámica económica y percepción social de los cambios recientes en la localidad fronteriza de Villa La Angostura, Pcia. del Neuquén. El impacto en la gestión gubernamental y en el desarrollo local. En: Córdoba, IV Seminario Nacional de la Red Muni I. Articulaciones interinstitucionales para el desarrollo local, 27 y 28 de octubre de 2008.

MARCHISSIO, M. Migrantes de amenidad. Nuevos emprendedores del sector turístico. Estudio de caso: El Bolsón y Lago Puelo. Tesina licenciatura en Turismo. Neuquén: Facultad de Turismo, Universidad Nacional del Comahue, 2007.

MEJÍA, J. El muestreo en la investigación cualitativa. Investigaciones Sociales, 2000, $\mathrm{N}^{\circ}$ 5, p. 169-170.
MOSS, L. Next steps and the Ionger view. In: MOSS, L. The amenity migrants. Seeking and sustaining mountains and their cultures. Trowbridge: Cromwell Press, 2006, p. 309-319.

NAKAYAMA, L. y MARIONI, S. Migración por opción: el fenómeno migratorio en destinos turísticos de montaña. En: AEPA. Libro de Resúmenes de la IX Jornadas Argentinas de Estudios de Población, Huerta Grande, Córdoba, Argentina. Córdoba: AEPA, 2007, p. 63-64.

NAKAYAMA, L.; MARIONI, S.; LONAC, A. y OTERO, A. Interacciones y efectos sobre el desarrollo local. El caso de San Martín de los Andes y el Parque Nacional Lanín. Aportes y Transferencias. Tiempo Libre, Turismo y Recreación, 2005, No I, p. 11-34.

SHELLER, M. Demobilizing and remobilizing Caribbean Paradise. En: SHELLER, M. \& URRY, J. Tourism Mobilities Places To Play, Places In Play. London: Routledge, 2004, p. 13-21.

SHELLER, M. \& URRY, J. Places to play, places in play. En: SHELLER, M. \& URRY, J. Tourism Mobilities Places To Play, Places In Play. London: Routledge, 2004, p. 1-15.

SOUTO, X. ¿Agua para todos o para la especulación urbanística? Biblio $3 W$ Revista Bibliográfica de Geografía y Ciencias Sociales, 2006, vol. XI, No 657. Disponible en Internet: http://www.ub.es/geocrit/b3w657.htm

THE CHINOOK INSTITUTE FOR COMMUNITY STEWARDSHIPS. The Open Space Toolkit for Alberta. Alberta's Natural Amenities Rush. Canmore: The Chinook Institute for Community Stewardships, 2005.

URRY, J. Death in Venice. In: SHELLER, M. \& URRY, J. Tourism mobilities places to play, places in play. London: Routledge, 2004, p. 206-215.

WILliaMS, P.; GILL, A. \& MOORE, S. Amenity migration's impact on affordable housing: a case study of Whistler, B.C. Victoria: Simon Fraser University, 1993. 